\title{
A traceable maturity assessment method based on Enterprise Architecture modelling
}

\author{
Ricardo Vieira \\ IST - University of Lisbon and \\ INESC-ID - Information Systems Group \\ Lisbon, Portugal \\ Email: rjcv@ist.utl.pt \\ Elsa Cardoso \\ ISCTE - Instituto Universitário de Lisboa and \\ INESC-ID - Information Systems Group \\ Lisbon, Portugal \\ Email: elsa.cardoso@iscte.pt
}

\author{
Christoph Becker \\ University of Toronto and \\ Vienna University of Technology \\ Canada / Austria \\ Email: christoph.becker@utoronto.ca
}

\begin{abstract}
Maturity assessments of business processes and capabilities are powerful tools for organizational improvement. Business process modelling is a key activity in the assessment of organizational maturity and capability of processes. However, the resulting models are complex and can often not be communicated successfully to the organizational stakeholders. Similarly, assessment methods rely strongly on the expertise of the assessors translating their perception of an organization into an assessment outcome. These assessments often carry a subjective component and are hard to compare. Moreover, they lack efficient traceability mechanisms as organizations evolve. Additionally, mainstream methods such as ISO 15504 and SCAMPI are complex, expensive and resource demanding, which place them out of reach for many organizations.
\end{abstract}

This paper describes a research approach that builds on Enterprise Architecture models and IT Governance frameworks to guide the definition of a simple process metamodel for maturity assessment. This simple meta-model is used to create an intermediary representation that can be communicated to stakeholders. A formal expression of maturity conditions in SPARQL queries increases the objectivity of the assessment and separates it from the collected and formalized evidence. We discuss our model and method and report on a preliminary case study.

\section{INTRODUCTION}

Maturity assessments of business processes and capabilities are powerful tools for organizational improvement. Business process modelling is a key component and core activity in the assessment of organizational maturity and capability of processes. However, the resulting process models are generally complex and can often not be communicated successfully to the organizational stakeholders. Similarly, assessment methods rely strongly on the expertise of the assessors translating their perception of an organization into an assessment outcome. These assessments often carry a subjective component and are hard to compare.

Business process models can range from informal models used by business users to describe how work is performed to more formal models used by software developers to specify how the process should be implemented. Software developers tend to design complex diagrams, full of details that business users take no interest in [1]. For the assessment purpose the level of detail of the process models is closer to the models developed by software developers, even if the goal is not to generate code from these diagrams. A business process modelling notation like BPMN can be used to diagram these complex processes, due to its large set of symbols. However, the level of detail present in these diagrams would overwhelm most assessment stakeholders. 'Business people model to simplify, highlight, clarify, and communicate. Thus any notation that makes things too complex is counterproductive' [1, p. 233].

As a result, stakeholders in the organization find it often difficult to understand the assessment results and how the evidence collected has been interpreted. There are few effective communication mechanisms to verify whether the assessor has represented the organization correctly. Assessments are inherently dependent on the assessor and the competencies of this assessor, and two assessments will often arrive at different results.

Assessment methods have to capture a wide variety of possible scenarios and be applicable across different contexts. This generally leads to heavy-weight approaches that require considerable expenses to be successfully applied. The reliance on "competent assessors" implies considerable costs to the assessed organization. But without experienced assessors, the assessment results will often not be considered trustworthy, since the methods and models themselves do not support lowcost verification and validation.

As an effect, current assessment methods such as ISO 15504 and SCAMPI are complex, expensive and resource demanding, which places them out of reach for many organizations and makes them a problematic choice for others who are looking for more effective mechanisms.

In practice, on the other hand, this leads to hand-crafted approaches that are often domain specific. These are perceived as useful by a certain user community, but are very limited in nature. One example is the domain of digital preservation, where the demand for trust on a digital archive to hold information reliably over long time spans has raised the question of trustworthy assessment. Here, two things have happened: Standards have emerged that prescribe what the organizations should do and which evidence they should present to demonstrate that they are doing it [2]. On the other hand, noting the complexity and prescriptive nature of these approaches, organizations such as national memory institutions have developed simple approaches to assessment. These are not built on established Information Systems principles and frameworks, but instead take a decidedly pragmatic stance and define simple criteria based on the expertise and current experience of their 
creators, who are considered domain experts in that field. The limitations of these approaches are increasingly recognized. However, the application of heavy-weight mainstream methods such as ISO 15504 is not seen as desirable and feasible in many scenarios. Instead, a middle way is sought to identify a balance between rigid standardized assessments requiring expensive consultation and training, and low-cost assessments that are inherently, and overly, subjective [3].

This paper describes a research approach that uses the key concepts of Enterprise Architecture, Archimate and COBIT ${ }^{1}$ to guide the definition of a process metamodel for maturity and capability assessment. This simple meta-model is used to create and intermediary representation that can be communicated to stakeholders. The COBIT 4.1 maturity tables are mapped into the meta-model concepts. This enables us also to represent maturity conditions in SPARQL queries and hence ensure objectivity in the assessment, based on collected and formalized evidence. We are evaluating the approach in the domain of digital preservation and are reporting on preliminary results of a pilot case. This paper is structured as follows. Section II outlines background work in the area of capability maturity models, process assessment, and requirements from a field currently struggling with establishing assessment and improvement mechanisms. Section III describes our approach for model-based assessment, while Section IV describes the assessment method in detail. Section V reports on a pilot case assessing the maturity of a process, while Section VI summarizes the contributions, reflects critically on the state of the art, and provides an outlook to future work.

\section{Capability and Process Assessment}

This section outlines key frameworks in the areas of capability maturity modelling and assessment, process assessment standards, and business process models. Based on a discussion of the relationships between these, we draw observations about the fitness for purpose of mainstream approaches.

It has been demonstrated that formal maturity models such as the Capability Maturity Model Integration (CMMI) are powerful tools for targeted improvement of processes based on quantitative assessment and gap analysis [4], [5]. IT Governance frameworks provide powerful controls for measuring processes both internally and externally through process and activity metrics and goal fulfilment [6].

While a broad variety of approaches exist, two major assessment approaches stand out. These generally consist of a methodical framework for conducting assessments; a conceptual framework of capability, maturity, and process modelling; and a set of modelling constructs to be used in the process of assessment.

The Capability Maturity Model series developed by the Software Engineering Institute and its SCAMPI assessment method may be the best known approach in the area. It has been shown to be a powerful instrument for assessment and improvement [4]. By assessing the maturity of organizations,

${ }^{1}$ COBIT newest version (COBIT5) proposes ISO 15504 as an approach to maturity assessment. However, as stated above, the complexity and prescriptive nature of the standard hinders the application in many scenarios. Therefore, in this paper we guide our maturity assessment using COBIT 4.1 approach on maturity tables. a certain level of comparability is achieved, and the trust in the reliability of their performance increases. However, the framework has been critized for its sometimes confusing model, distinguishing between staged and continuous representations, and for requiring substantial resource commitment for its application [7].

Similar criticism has been voiced over ISO 15504, which originated from the earlier "Software Process Improvement and Capability Evaluation" (SPICE) [8]. ISO 15504 is a set of standards that defines an overall framework for assessment including criteria for assessment and an assessment method. ISO 15504 requires the definition of a process reference model, 'comprising definitions of processes in a life cycle described in terms of process purpose and outcomes, together with an architecture describing the relationships between the processes' $[9$, p. 12]. Based on this reference model and a measurement framework, a process assessment model needs to be created, against which an organization's process can then be assessed through a formal assessment process. The standard strives to "maximize the repeatability, reliability and consistency of assessments" [9, p. 14] by requiring formal documentation of evidence, and requires that a compliant assessment be conducted by a competent assessor with requirements on formal education, certification, and experience [10].

The capability of processes is measured by sets of defined process attributes rated on a four-point scale. The maturity of an organization, on the other hand, is determined by a complex mapping, relying on process capability levels and an organizational maturity model. Performing a full process assessment and determining process capability levels are necessary prerequisites for the assessment of organizational maturity [11].

In the domain of IT Governance, COBIT 4.1 proposed a much simpler assessment of maturity with a flexible table that distinguishes different dimensions of maturity [6]:

1) Awareness and Communication

2) Policies, Plans and Procedures

3) Tools and Automation

4) Skills and Expertise

5) Responsibility and Accountability

6) Goal setting and Measurement.

In each of these dimensions, an assessment can be done on a scale from 1 to 5 with increasing maturity. The flexibility of this approach makes it easy for organizations to see their strengths and weaknesses. It is natural in an organizational setting that for example awareness and communication improves with respect to a certain process before formal responsibility is assigned. However, COBIT 5 has moved to a more standardsbased approach and proposes to rely entirely on ISO 15504 for process assessment.

Essentially, an assessment of an organization creates a mapping from the universe of discourse to a set of indicators that are agreed, in a certain community, to possess value in a decision making context. These can be indicators of performance and capacity, but also indicators of trust or, in our case, maturity. Assessment methods are conceptual frameworks and operational procedures for arriving at an assessment result for a given organization. Figure 1 illustrates this. A challenge hereby is that commonly, the stakeholders in the assessed organization 


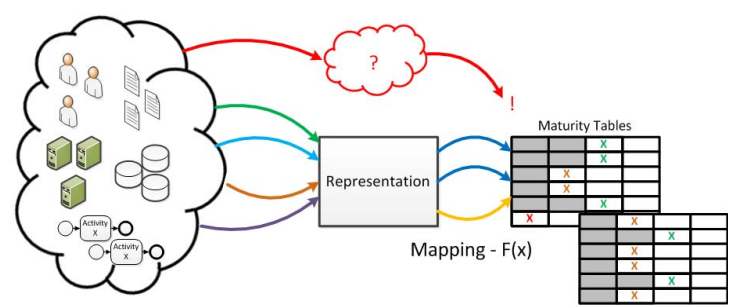

Fig. 1. Assessment of maturity in a monolithic approach poses challenges of understandability and traceability

do not possess the capacity, expertise and skills to conduct such an assessment themselves. Hence, an assessor conducts the assessment and presents the results, which raises the question of representativeness of the assessment and how understandable the results are to the decision makers. It would be desirable to facilitate stakeholder communication over an intermediary representation, but such a representation commonly does not exist.

ISO 15504 and CMMI define sets of relationships between what is done (process areas) and how certain things need to be done for a capability to be achieved, and in turn how these translate into organizational maturity. These relationships are complex, which makes them hard to understand for practitioners without dedicated expert's assistance. The intermediary steps between the universe of discourse (an organization) and the assessment results (a report) remain opaque to the decision makers. drawn.

Based on this discussion, several observations can be

- The traceability of the assessment and the understandability of the results to the stakeholders of the organization that is being assessed pose a challenge.

- The lack of an intermediary representation that can be communicated to and corroborated by the organization's stakeholder makes it more difficult to assess the trust one can place in an assessment.

- Enterprise Architecture frameworks (e.g. TOGAF [12]) have been proposed to address similar concerns of representation and communication and may hence provide a useful level of abstraction to employ in this context.

- Heavy-weight assessment methods are not always applicable and effective.

- Assessment approaches that are domain-specific often fail to distinguish between an assessment of goals and outcomes, maturity in achieving such outcomes, and mechanisms for achieving such outcomes. Instead of assessing results, they prescribe what is perceived as the current state of the art in a community on how to achieve specific outcomes. This makes the models prone to becoming irrelevant and counterproductive as the state of a discipline advances.

The next section will outline an approach to address the perceived shortcomings by developing an approach that aims to fill the identified gap. We will then report on preliminary experiences with that approach and outline further steps.

\section{EA-BASED ASSESSMENT}

\section{A. Approach}

To close the gap between highly complex assessment methods with considerable investment that are partially proprietary, we are developing an assessment approach using an intermediary process metamodel and formalized conditions of maturity on a set of dimensions. A number of key principles guide the design of the approach, including the following.

1) Applicability across domains. Assessment of maturity should ideally be applicable across a broad range of domains. More importantly perhaps, it should be possible to assess the applicability of the approach in a certain domain.

2) Descriptive, not prescriptive. As highlighted above, prescriptive models are prone to becoming irrelevant and counterproductive, as they hamper innovation and are inflexible with respect to change. One key principle hence is to avoid prescriptive criteria and conditions.

3) Low barrier to adoption. A general overarching goal is to minimize the barriers to adoption. This pertains both to the openness of the models and methods and to the effort and expertise required to conduct assessments.

4) Simplicity and minimalism. Both as a design principle and as a means to contribute to a lower adoption barrier, the 'return on investment' for any element added to the model has to be justified thoroughly as part of the design process.

5) Modularity as a crucial design principle contributes not only to the robustness of the model and to a separation of concerns, but also to its maintainability. As such, the aim is to design a minimal kernel for maturity assessment that can be extended as needed for specific needs.

6) Trust and trustworthiness address the need for stakeholders to rely on the assessment and base business decisions on its results. Without a certification process such as ISO 15504, the design of the model needs to provide mechanisms for verification, traceability and transparency to facilitate the trust of stakeholders.

7) Rigour and traceability are essential for the design process and the resulting artifacts. We are following a design science research methodology (see for example [13], [14]).

It is clear that these principles can get into conflict. Potential conflicts may arise between traceability and simplicity or between rigour and a low barrier to adoption. However, these principles can act and have acted as guiding principles in decision points when building the metamodel and method. While the broader work on this approach involves the definition of capabilities and capability levels for a set of domain-specific capabilities, this paper focuses on the assessment of maturity of a given process. 


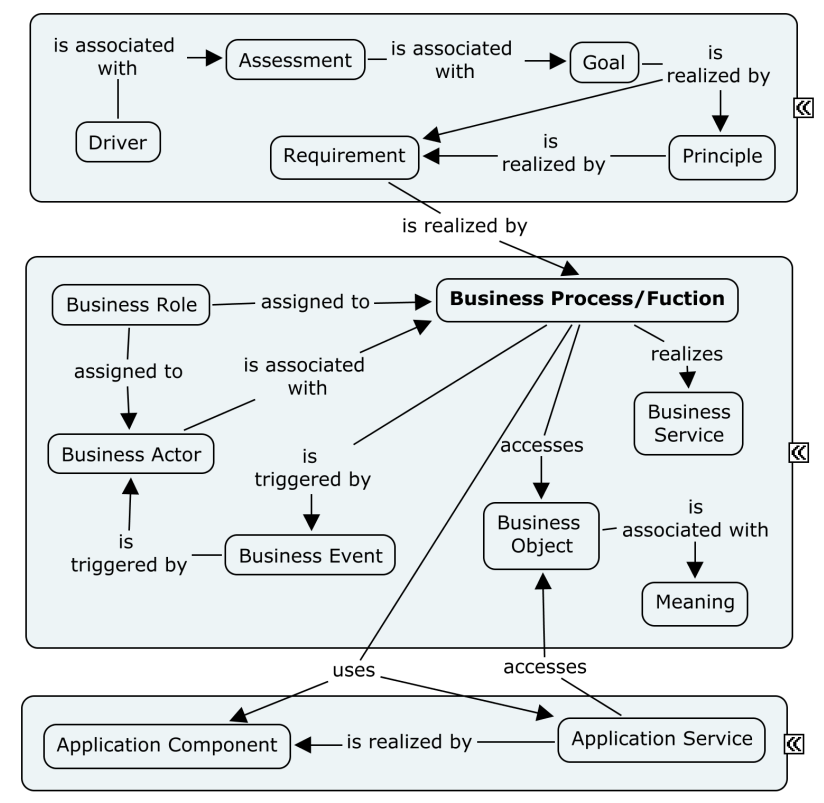

Fig. 2. Process Metamodel

\section{B. Process Metamodel}

An essential step for process improvement is to properly understand the process. However, assessment approaches such as ISO/IEC 15504 only specify that processes under assessment must be defined with a title, a purpose, and a series of outcomes [15]. Due to the vague definition of those concepts, process definitions strongly depend on the person(s) describing the process. For example, while some identify the steps of the process as part of its purpose, others see purpose as a simple statement regarding the business goal of the process. This leaves the assessors with few or no control over the level of detail of the process to be assessed, thus hindering its correct evaluation.

One prominent approach to address this is to integrate process modelling with assessments. This allows more descriptive process definitions and consequently can lead to a more accurate processes assessment [16]. Since the beginning of the 20th century, several techniques (e.g. flow charts, activity diagrams, UML, etc.) to model process emerged. Nowadays, Business Process Model and Notation (BPMN) [17] stands as one of the most known and used techniques to model processes. BPMN uses three types of models to capture a process: (1) a functional model to describe processes and their structure, (2) an object model to describe entities that are exchanged through those processes, and (3) a coordination model to describe how entities relate and interact with the activities of the process [16]. Although BPMN models are without a doubt a very useful tool for process modelling, they are only one component required for a holistic Enterprise Architecture view [18]. In fact, while BPMN models can proper describe business process flows, they lack the concepts to properly describe structural aspects such as actors, data objects, IT infrastructure components, etc. [18].

EA models aim to provide a holistic architectural view of a process by contextualizing it through different perspective layers. The Archimate EA modelling language was developed to provide a uniform representation for diagrams that describe enterprise architectures [19]. The core language is divided in three main types of elements: active structure elements that are capable of performing behaviour, behaviour elements that are units of activity that can be performed by one or more active structure elements, and passive structure elements defined as objects on which behaviour is performed [19]. The elements are divided in three main layers:

1) the business layer, where products and services are realized by business processes and functions and performed by business actors,

2) the application layer that supports the business layer by describing application services that are realized by (software) applications, and

3) the technology layer that supports the application layer by describing the infrastructure services required to run the application services [19].

Additionally, through a motivation extension layer, Archimate adds motivation concepts such as goals, principles, and requirements that provide the context or reason behind the architecture of an enterprise [19].

As described in section III-A, our approach is based on a set of design goals and principles. Using those as references, we were able to discuss and understand how Archimate could be used in our approach. As an EA modelling language, Archimate was designed to be applicable to different domains. In fact, through the use of the layers and different types of elements, Archimate allows different levels of abstraction, i.e., it supports generic and abstract descriptions of an organization that can be specialized using different architecture layers as explained above [19]. This level of modularity makes it particularly useful in our context. Another important aspect of Archimate is that
"it has been explicitly designed to be as small as possible, but still usable for most enterprise archi- tecture modelling tasks. In the interest of simplicity of learning and use, Archimate has been limited to the concepts that suffice for modelling the proverbial $80 \%$ of practical cases" [19].

This design restriction aligns with our design principles of low barrier to adoption, and simplicity and minimalism.

However, our principle of minimalism also states that our metamodel should stick to the minimal number of elements and relations necessary. Therefore, using the COBIT 4.1 Maturity Model [6], ISO 15504 process assessment [9], and SPICE [8] as references, we identified the minimum required set of concepts and relations required by our assessment goals. By using a reduced set of Archimate concepts and relations we assure reduce the learning curve of the metamodel and consequently reduce the barrier to adoption. Figure 2 illustrates our final reduced set of Archimate concepts for our process metamodel. At the motivation layer we use the concepts of driver, assessment, goal, requirement and principle. Those allow to define the motivation behind business process or functions that can (1) be assigned to roles or actors, (2) be triggered by business events, (3) realize a business service, and/or (4) access a business object with a specific meaning. At the 

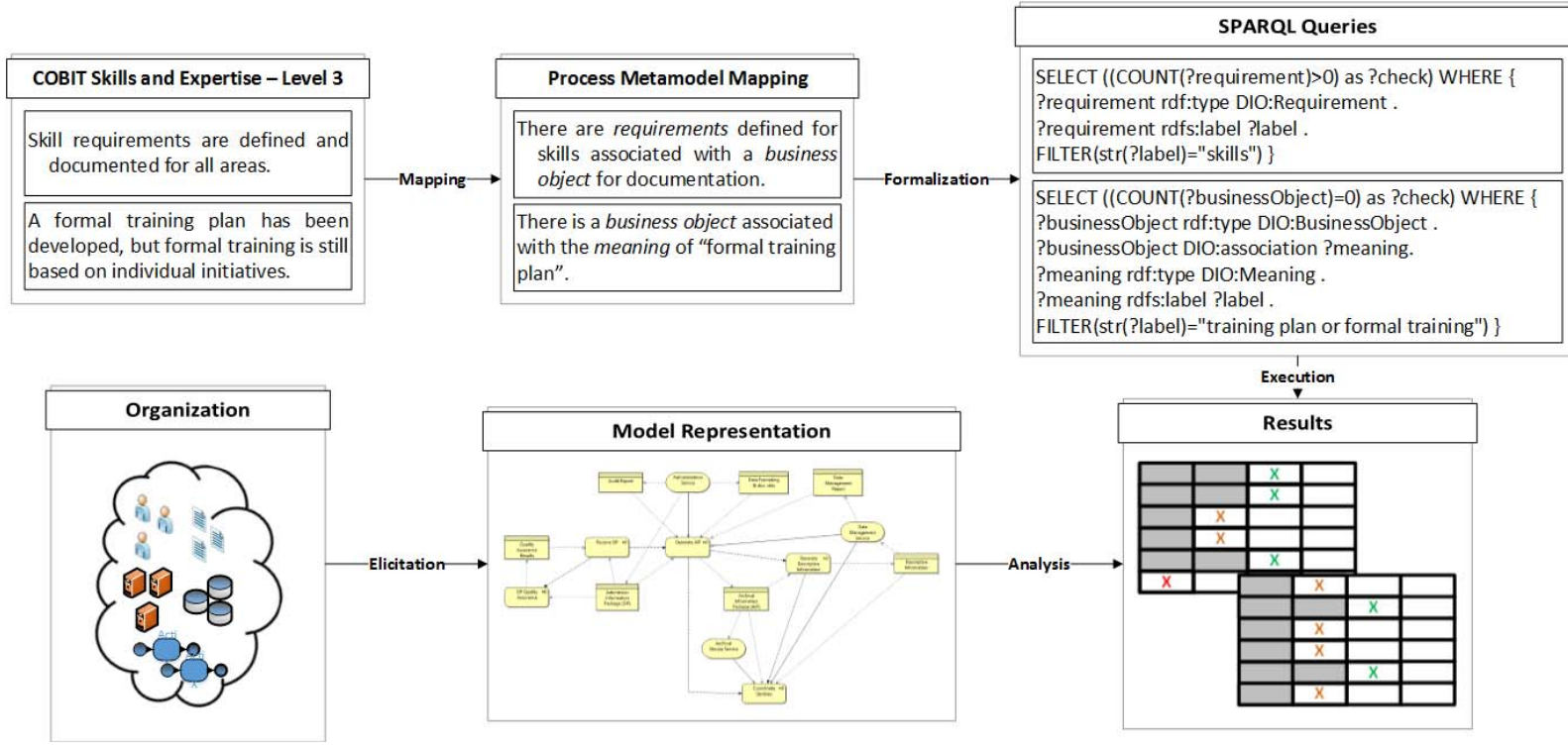

Fig. 3. Process maturity assessment approach

application layer, we only consider the concepts of application service and application component. The technological layer of Archimate is left out since detailed technological assessment of the process is not required by the maturity criteria.

\section{Maturity Mapping}

The COBIT 4.1 Maturity Model was designed to allow an organization to assess how well developed its processes are. Additionally, through the use of the maturity table, organizations can set their target levels, identify their strong and weak points, and plan targeted process improvement. The Maturity Model is built from a generic qualitative model that defines that a process maturity level can range from 0 (Non-existent) to 5 (Optimised). The generic model describes, for each level, which principles should be satisfied. Those principles are then translated through the dimensions of (1) Awareness and communication, (2) Policies, plans and procedures, (3) Tools and automation, (4) Skills and expertise, (5) Responsibility and accountability, (6) Goal setting and measurement [6]. This organization of the maturity model satisfies our principle of modularity.

However, due to the fact that COBIT 4.1 only defines general principles for the determination of the maturity level, the application of the maturity model is often highly subjective [20]. This subjectivity creates a strong dependence between the assessment results and the understanding of the principles by the assessor. Additionally, due to the lack of formalization in the maturity model, assesses have difficulties understanding the how the results were obtained, i.e., there is a lack of traceability between the assessment findings and the results [20]. In other words, the COBIT model application does not satisfy our principle of trust and trustworthiness, especially due to the lack of rigor and traceability.

In our approach, the COBIT 4.1 maturity principles are mapped to formalized statements using the concepts of our process metamodel. Therefore, assessees only have to agree on the representation of the process being assessed. Upon that, the formal statements can be used to assess, according to the representation, the maturity level of the process. Due to the fact that we use Archimate concepts, this also allows us to create a model representation of the process being assessed. This Archimate model can further be converted ${ }^{2}$ to an OWL ontology file supporting querying and reasoning upon the model. By converting each of our statements to SPARQL queries, we hence can automate the analysis of the model by simply executing the queries on the OWL file. This improvement of the application of the COBIT 4.1 Maturity Model allows us to satisfy our principle of trust and trustworthiness as follows:

1) The use of a process modelling language improves understandability of the conclusions of the assessment,

2) the use of formal statements using Archimate concepts improves rigor on the assessment, and

3) the use of queries to assess the maturity level allows a clear traceability between evidence, scoring and rating.

Figure 3 illustrates the main conceptual steps and intermediary artifacts of the approach. At the top left of the diagram we see, as an example, the conditions stated on COBIT 4.1 level 3, dimension skills and expertise. Those were then mapped to statements using the concepts in our process metamodel. So, as illustrated, the definition of requirements for skills associated with a business object indicates that skill requirements are defined and documented. The statements were then formalized to equivalent SPARQL Queries. In this way, using elicitation (see Section IV), we can model our representation of the process using Archimate and, through the execution of the queries and analysis of the model, assess the maturity level of that process.

\footnotetext{
${ }^{2}$ using work done on the European project TIMBUS: Timeless Business Processes and Services, http://timbusproject.net/
} 


\begin{tabular}{|c|c|c|c|c|c|c|}
\hline & $\begin{array}{l}\text { Awareness and } \\
\text { Communication }\end{array}$ & Policies, Plans and Procedures & Tools and Automation & Skills and Expertise & $\begin{array}{l}\text { Responsibility and } \\
\text { accountability }\end{array}$ & $\begin{array}{l}\text { Goal setting and } \\
\text { Measurement }\end{array}$ \\
\hline 1 & $\begin{array}{l}\text { There is a business event } \\
\text { for "communicating } \\
\text { issues" that is triggered by } \\
\text { a business actor. } \\
\text { There is a driver for } \\
\text { defining a business } \\
\text { process. }\end{array}$ & $\begin{array}{l}\text { There is no Business Process. } \\
\text { There are no requirements defined for } \\
\text { procedures and policies. }\end{array}$ & $\begin{array}{l}\text { There is at least one } \\
\text { application component } \\
\text { associated with a business } \\
\text { process. } \\
\text { There are no requirements } \\
\text { for "tool usage". }\end{array}$ & $\begin{array}{l}\text { There are no skills requirements. } \\
\text { There is no business object } \\
\text { associated with the meaning of } \\
\text { "training plan or formal training". }\end{array}$ & $\begin{array}{l}\text { There are no business roles } \\
\text { defined. } \\
\text { There may be business actors } \\
\text { identified but without business } \\
\text { roles being assigned. }\end{array}$ & $\begin{array}{l}\text { There are no goals defined and } \\
\text { no requirements for } \\
\text { measurement. }\end{array}$ \\
\hline 2 & $\begin{array}{l}\text { There is a requirement to } \\
\text { define a business service. } \\
\text { There is a Business Event } \\
\text { raised to communicate } \\
\text { issues associated with a } \\
\text { business role and/or a } \\
\text { business actor of } \\
\text { management level. }\end{array}$ & $\begin{array}{l}\text { There is at least one business process. } \\
\text { There are business processes that are associated } \\
\text { with business actors. } \\
\text { There are requirements statements about the } \\
\text { business process being defined. }\end{array}$ & $\begin{array}{l}\text { There are requirements for } \\
\text { "tool usage" associated with } \\
\text { at least one business } \\
\text { process (local solution). }\end{array}$ & $\begin{array}{l}\text { There are requirements for skills } \\
\text { defined, but not for all business } \\
\text { processes. } \\
\text { There is a business event for } \\
\text { requesting training that triggers } \\
\text { the execution of a training } \\
\text { business event. }\end{array}$ & $\begin{array}{l}\text { When a business event } \\
\text { regarding "issues" is triggered } \\
\text { it does not access the business } \\
\text { object associated with the } \\
\text { meaning of "responsibility". }\end{array}$ & $\begin{array}{l}\text { There are some goals defined. } \\
\text { There is a requirement for } \\
\text { financial measures that is only } \\
\text { associated with the business } \\
\text { role of senior management. } \\
\text { There is a business object } \\
\text { which is associated with the } \\
\text { meaning of measures. }\end{array}$ \\
\hline 3 & $\begin{array}{l}\text { There is an assessment } \\
\text { associated with the driver } \\
\text { for defining a business } \\
\text { process associated with a } \\
\text { business service. } \\
\text { There is a business } \\
\text { process or business } \\
\text { function for } \\
\text { communication. }\end{array}$ & $\begin{array}{l}\text { There is a Business Object associated with the } \\
\text { meaning "good practices". There is a business } \\
\text { process that is associated with a Business } \\
\text { Object associated with the meaning "good } \\
\text { practices". } \\
\text { There is a principle so that process, policies and } \\
\text { procedures are documented. There is a business } \\
\text { object associated with the meaning of } \\
\text { documentation for every business process. There } \\
\text { is a business object associated with the } \\
\text { meaning of policy and procedures. }\end{array}$ & $\begin{array}{l}\text { There is a Business Object } \\
\text { associated with the meaning } \\
\text { "plan for use and standardi-- } \\
\text { zation of tools to automate } \\
\text { the process". There is an } \\
\text { application service } \\
\text { associated with this } \\
\text { business object. There are } \\
\text { business processes that use } \\
\text { an application component } \\
\text { instead of the application } \\
\text { service. }\end{array}$ & $\begin{array}{l}\text { There are skill requirements } \\
\text { defined and documented } \\
\text { (associated) with a business } \\
\text { object. } \\
\text { There is a business object } \\
\text { associated with the meaning of } \\
\text { "formal training plan". }\end{array}$ & $\begin{array}{l}\text { The business roles for a } \\
\text { business process are } \\
\text { identified. The business role } \\
\text { of the process owner is } \\
\text { identified. }\end{array}$ & $\begin{array}{l}\text { There is an assessment for } \\
\text { measurement associated to } \\
\text { business goals. } \\
\text { There is no business process } \\
\text { for communication of } \\
\text { measurements. } \\
\text { There is a business process for } \\
\text { process measurement. } \\
\text { There is a requirement for } \\
\text { effectiveness measures. }\end{array}$ \\
\hline 4 & $\begin{array}{l}\text { All requirements are } \\
\text { associated with the } \\
\text { business process for } \\
\text { communication. } \\
\text { There is a principle } \\
\text { (Policy) for applying } \\
\text { mature communication } \\
\text { techniques. } \\
\text { The business process for } \\
\text { communication uses } \\
\text { application } \\
\text { component(s). }\end{array}$ & $\begin{array}{l}\text { There is a business process for compliance } \\
\text { checking of: (1) Internal best practices; ( } 2 \text { ) } \\
\text { Requirements of the Processes and ( }(3) \\
\text { Standards for developing and maintaining the } \\
\text { processes and procedures. There is a business } \\
\text { process for documenting business processes. } \\
\text { There is a business object associated with the } \\
\text { meaning of "approved and signed off policies } \\
\text { by management". There is a business process } \\
\text { for approving business processes policies } \\
\text { associated with the business role of } \\
\text { management level. There is a business object } \\
\text { associated with the meaning of "process } \\
\text { documentation". }\end{array}$ & $\begin{array}{l}\text { All business process use the } \\
\text { application service defined } \\
\text { in the previous level. } \\
\text { There is a Business Process } \\
\text { to manage and monitor } \\
\text { critical activities and } \\
\text { controls of processes. This } \\
\text { business process uses an } \\
\text { application component. }\end{array}$ & $\begin{array}{l}\text { There is a business process for } \\
\text { "skill requirements } \\
\text { management". The process needs } \\
\text { to ensure that skill requirements } \\
\text { are updated, proficiency is } \\
\text { ensured and certification } \\
\text { encouraged. } \\
\text { There is a principle (Policy) for } \\
\text { applying "Mature training } \\
\text { techniques and encouraging } \\
\text { knowledge sharing". There is a } \\
\text { business process to assess the } \\
\text { business plan. }\end{array}$ & $\begin{array}{l}\text { There is a principle (policy) } \\
\text { that formally expresses the } \\
\text { authority of process owners, } \\
\text { and encourages a reward } \\
\text { culture (positive management). }\end{array}$ & $\begin{array}{l}\text { There is a business process for } \\
\text { communication of } \\
\text { measurements. } \\
\text { There is a business object } \\
\text { associated with the meaning } \\
\text { "IT Strategic Plan". Business } \\
\text { goals are associated with this } \\
\text { business object. There is a } \\
\text { requirement for efficiency } \\
\text { measures. There is a driver for } \\
\text { continuous improvement. } \\
\text { There is a business process for } \\
\text { analysis of how requirements } \\
\text { are met. }\end{array}$ \\
\hline 5 & $\begin{array}{l}\text { Requirements are } \\
\text { managed pro-actively (i.e. } \\
\text { there is a business } \\
\text { process to identify new } \\
\text { and review existing } \\
\text { requirements). } \\
\text { The business process for } \\
\text { communication uses an } \\
\text { integrated solution } \\
\text { associated with an } \\
\text { application service. }\end{array}$ & $\begin{array}{l}\text { There is a business object associated with the } \\
\text { meaning of "external best practices and } \\
\text { standards". There is business process associated } \\
\text { with that business object. The business process } \\
\text { for documenting business processes is associated } \\
\text { with an application service. There is a principle } \\
\text { for standardizing and integrating processes, } \\
\text { policies and procedures enabling a systemic and } \\
\text { end-to-end management and improvement. }\end{array}$ & $\begin{array}{l}\text { All application } \\
\text { components realize an } \\
\text { application service. } \\
\text { The Business Process used } \\
\text { to manage and monitor } \\
\text { critical activities and } \\
\text { controls of processes, uses } \\
\text { an application service for } \\
\text { improvement to "detect and } \\
\text { control exceptions". }\end{array}$ & $\begin{array}{l}\text { Personal and organizational goals } \\
\text { are defined. There is a principle } \\
\text { that encourages continuous } \\
\text { improvement of skills. There is a } \\
\text { business function for research } \\
\text { and development making the link } \\
\text { to external best practices and } \\
\text { standards (projects, committees). } \\
\text { There is at least one application } \\
\text { component for enterprise } \\
\text { knowledge sharing. }\end{array}$ & $\begin{array}{l}\text { Process owners act as driver } \\
\text { for business transformation, } \\
\text { encouraging proactive } \\
\text { management. } \\
\text { The business role of process } \\
\text { owner is associated with this } \\
\text { driver. } \\
\text { Business roles are } \\
\text { decomposed into specialized } \\
\text { business roles in a consistent } \\
\text { way. }\end{array}$ & $\begin{array}{l}\text { There is business function for } \\
\text { performance management } \\
\text { linking IT performance to } \\
\text { business goals. There may be } \\
\text { an application service being } \\
\text { used by this business } \\
\text { function. } \\
\text { There is a principle for } \\
\text { "continuous improvement". }\end{array}$ \\
\hline
\end{tabular}

Fig. 4. COBIT 4.1 Maturity Table Mapping

The complete set of conditions on the process metamodel concepts which are used for each level and each dimension is provided in Figure 4.

\section{Elicitation: The ASSESSMENT METHOD}

This section describes the key elements of an open and modular assessment method guided by the principles described above. The business process assessment method (see Figure 5) comprises four phases: pre-assessment, conduct assessment, analysis and reporting, and feedback. The main focus of the assessment method is not to judge the maturity of an organization, but to elicit knowledge about their process and enable its representation in the process model (hence elicitation).

\section{A. Phase 1: Pre-assessment}

The main goal of the Pre-assessment phase is to plan the assessment exercise and set the right expectations with the organization being assessed. This phase entails a face-to-face meeting with the stakeholders that must occur a few days prior to the assessment date, and a planning activity, performed by the assessment team.

In the pre-assessment meeting, the stakeholders are informed of the goals and outcomes of the assessment exercise and receive the Assessment Checklist document.
The main goal of this meeting is to determine the scope of the assessment. The assessment team and the stakeholders must identify the most useful processes to be assessed and the list of participants that need to be present during the assessment day. The Assessment Checklist document contains a list of documents that the organization must compile in order to enable the assessment of capability and maturity levels of the selected process. The checklist must be explained to the stakeholders to ensure that useful evidence will be gathered during the assessment. This is a crucial point: the assessment team needs to guarantee that the stakeholders are aligned with the terminology used in the assessment method (both domain specific and modelling concepts). In the planning activity, the assessment team develops the Assessment Plan document, taking into account the information gathered during the preassessment meeting. The Assessment Plan specifies the following items: (1) goals; (2) outcomes; (3) scope; (4) assessment constraints; (5) detailed schedule for the assessment day; and (6) list of participants with role specification.

The following roles have been specified for the assessment team:

- The Facilitator leads the assessment, performs the interview and is the main interlocutor with the stakeholders. 


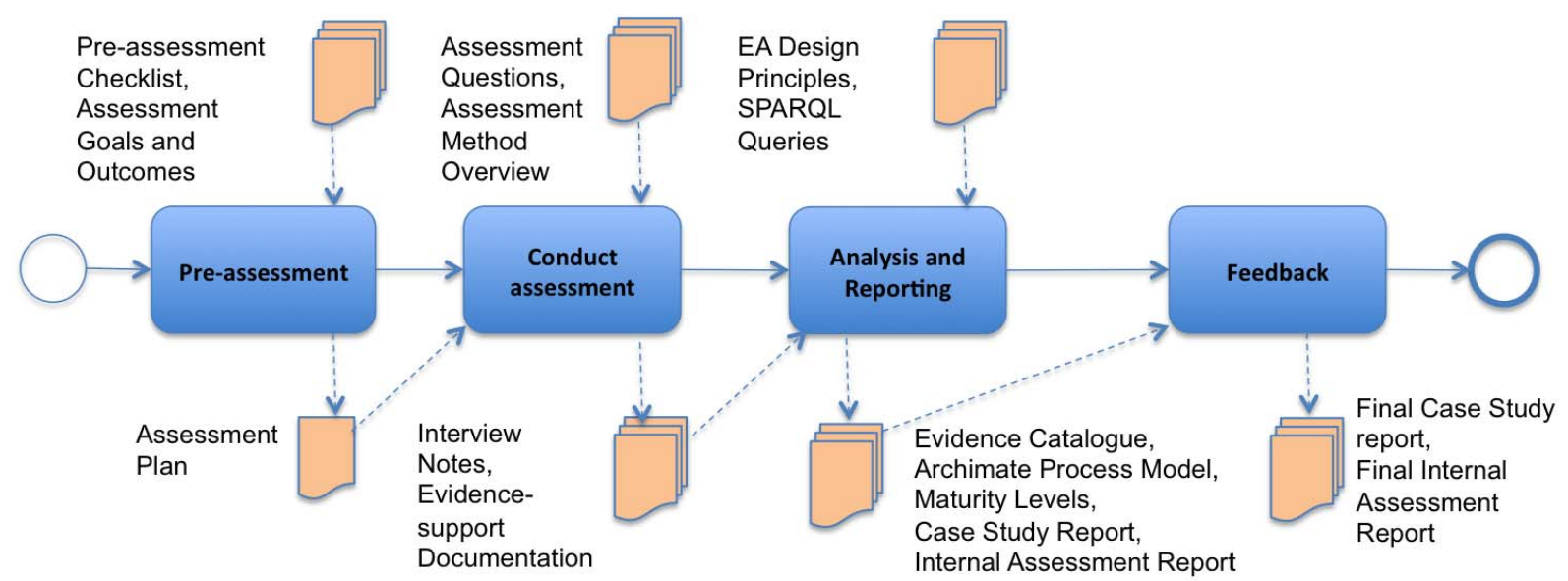

Fig. 5. Assessment Method

- The Concept collector and monitor identifies the elements in the process metamodel during the interview, and also checks for coverage of elements, notifying the facilitator when gaps are apparent.

- The Scribe is responsible for taking extensive notes during the interview.

- The Timekeeper is also assigned to the facilitator, who needs to ensure that the assessment schedule is followed.

- The case study research leader, finally, ensures consistency of the assessment method through all case studies.

\section{B. Phase 2: Conduct Assessment}

The Conduct Assessment phase takes place during the assessment day, and comprises the following steps: briefing, assessment interview, and collect documentation. This phase starts with a briefing session (which should not exceed 30 minutes) with a round of introduction by each participant, followed by the presentation of the assessment goals and outcomes, and a high-level description of the assessment method (based on the Assessment Method Overview document, which is then distributed to the stakeholders). Finally, the schedule and the assessment team roles are also presented.

The Assessment Interview step is lead by the facilitator using a simple interview protocol to gather the required evidence for the assessment. The protocol uses a semi-structured interview, starting with a set of general questions and then specific questions related to each of the six maturity dimensions of COBIT 4.1 (as described in Section III). Whenever possible, the interview should be recorded to facilitate the consolidation of notes taken by the scribe. The goal is to perform a focused interview in order to use the stakeholders' time efficiently. However, the sequence of the questions needs to remain flexible in order to have the freedom to capture the insights and complexities of the process, which in turn will make the assessment exercise more fruitful for the organization. Note that one of the outcomes of value to the stakeholders is the discovery of improvement initiatives for the process.
Therefore, the interview session needs to be focused, but on the other hand flexible to enable the stakeholders to perform a critical reflection on how the process is executed. In this step the facilitator uses the Assessment Questions document to guide him through the sequence of questions. However, the facilitator is not bounded by these set of questions, follow-up questions may and should be asked to clarify and resolve gaps.

The final step Collect Documentation entails the gathering and selection of relevant documentation that support the stakeholders' answers to the assessment questions. Although the gathering part occurs concurrently with the interviews, the selection part needs to be performed at the end of the assessment day. The assessment team needs to ensure they leave with all the required documentation to elaborate the evidence catalogue. From the collection of documents provided, the team should select the subset that will be subjected to further analysis, which then constitutes the Evidence-support Documentation illustrated in Figure 5.

\section{Phase 3: Analysis and Reporting}

The main goal of the Analysis and Reporting phase is to elaborate an initial assessment report to be delivered to the stakeholders, as well as an internal report for the assessment team with a critical reflection on the assessment method. This phase is structured in four steps:

1) Definition of the evidence catalogue,

2) Design of the Archimate model of the process,

3) Determination of the maturity level, and

4) Reporting.

The first step, definition of the evidence catalogue, initiates with the transcription and consolidation of the interview notes into a single document. The evidence catalogue is defined using the interview notes and the Evidence-support Documentation. Next, the Archimate model of the assessed process is designed using the evidence catalogue and the EA Design principles. In the next step, determination of the maturity level, the assessment team uses the set SPARQL queries focused on process maturity determination (which can applied to different processes, i.e., are not process-specific). These queries enable the gathering of information to determine the maturity level for 
the six dimensions considered by COBIT 4.1. Finally, in the reporting step, two documents are produced: the Case Study Report, containing the analysis of the assessment exercise, which will be delivered to the stakeholders; and the Internal Assessment Report for the assessment team.

\section{Phase 4: Feedback}

The feedback phase entails a face-to-face meeting with the stakeholders and another reporting step. In the feedback meeting, the Case Study Report document will be revisited and the assessment team collects all the correction actions noted by the stakeholders. The discussion should focus on the findings of the assessment (e.g., if the capability and maturity levels match the stakeholders' expectations), as well as on the weaknesses and aspects for future improvement of the assessed process. Based on the interaction and feedback received by the stakeholders, the assessment team should iterate the reporting step and produce the final versions of the Case Study Report and the Internal Assessment Report.

\section{EVALUATION AND DISCUSSION}

The approach presented in this paper is piloted in a narrowly-defined case study to gain an appreciation of the particular strengths and weaknesses that the method entails, evaluate the feasibility of broader application, probe for particular challenges, and evaluate the understandability of the method for stakeholders. The initial broader application domain is digital preservation, and the case study focuses on the ingest process of one digital repository. This is the key process that manages the reception of digital objects into a repository as the key interface that repositories offer for depositors. Essentially, the Ingest process receives an information package from a client wishing to deposit it with the repository and acknowledges the receipt, confirming that the object has passed into the custody of the repository. In the domain of institutional repositories, this can be an electronic thesis completed at an academic institution or a journal article. In other scenarios, the information package can be a data set.

The first case study was performed in April 2014 at the Documentation and Information Services, hereafter referred to as library services of ISCTE - Instituto Universitário de Lisboa, a public university in Lisbon, Portugal. This pilot case study focused solely on the ingest process of the library services. The narrow scope of the assessment was purposefully chosen to enable a more concise and focused exercise, and yet still delivering relevant outcomes to the stakeholders. This pilot case was crucial to test the estimated duration of the steps of the Conduct Assessment phase as well as to gain a deeper insight on the strengths and weaknesses of this assessment approach. Therefore, this pilot exercise was used as an exploratory case study.

The assessment team was composed of four members who jointly performed the list of roles specified in the Elicitation section. The organizational stakeholders were the director and the coordinator of the training and information unit of the library services. The assessment focused mainly on the library repository. The stakeholders were asked to perform a demonstration of the ingest process, using a typical use case: the deposit of a master thesis in the repository.
Currently, the Analysis and Reporting phase is ongoing. However, it is still possible to report some preliminary results. First, the design decision to focus on one process rather than a broader assessment was acknowledged as a positive aspect of the assessment. The stakeholders reported that in the pre-assessment meeting, some parts of the discussions (which enable the identification of the organizational context and assessment constraints) appeared complex. They preferred the ingest scope-framed questions of the assessment interview. Second, length-wise, the stakeholders also perceived the assessment exercise as adequate. Finally, they were able to identify some small improvement actions to pursue in the near future (e.g., extending the same type of documentation already in use to other types of documents involved in the ingest process).

As described in Section IV-B, the interview started with a set of general questions and then specific questions related to each of the six maturity dimensions of COBIT 4.1. All questions were open-ended and for each it was identified the expected knowledge from the answers. General questions were based on our process metamodel, i.e., for each concept in the metamodel we identified a set of questions. For example, the questions "What is the purpose/mission of the organization?" and "How does the organization pursue its mission?" were asked in order to understand the main drivers and assessments of the organization. For the specific questions, we analysed our metamodel statements (see Section III-C) to identify questions that would allows us to get the level of detail required for the dimensions. As a simple example, to assess the statement illustrated in Figure 3 the following initial questions were asked: "(Q1) Which skills are required to perform the process?, (Q2) Are those skills documented?". For this particular example, the assesses were able to describe some skills, but unable to present documentation describing them, so we could conclude that although the organization has some skill requirements, these are not documented.

\section{CONCLUSION AND OUTLOOK}

This paper has outlined practical challenges with mainstream process assessment approaches and presented a method to decouple the assessment of maturity from the construction of a representation of an organization in order to facilitate an objective assessment of maturity in a generic, processindependent perspective. By moving the judgment of maturity from the assessment method to a query condition, the approach decouples elicitation of factual observations from the representation of these observations in a model and from the interpretation of the evidence according to a particular perspective. By representing maturity conditions as query projections, the approach can decrease the reliance on assessors for informed and fair judgment. This decoupling facilitates multiple interpretations and perspectives and can thus yield a number of benefits.

1) Efficiency and transparency. The process model together with the formulation of formal query conditions as expression of maturity provide a formal projection from a process model to a maturity assessment. This makes the assessment itself more efficient and transparent. 
2) Flexibility and traceability. Maturity assessment conditions can be adapted independently of elicitation. This enables re-assessment over time and according to multiple perspectives.

3) Communication and documentation. The intermediary representation can facilitate engagement with the stakeholders and allow them to verify the perception of the assessors.

4) Analysis and Scrutiny. The intermediary representation of processes enables systematic analysis of these enterprise models. Furthermore, by explicitly representing conditions in query statements, it becomes possible to scrutinize and criticize the conditions and the way they are formulated, but also develop alternative perspectives and compare results on the same set of collected evidence.

However, the approach comes with possible drawbacks and challenges.

1) There is a different kind of complexity in this approach, which puts the burden of correct representation into the hands of the metamodeler. The inherent limits of representation in modelling (cf. [21]) pose limits on the expressiveness of the conditions and the alignment with expert judgment. It may also still potentially be a challenge to communicate the models. Will stakeholders agree on their meaning? This really is an instance of the broader test that Enterprise Architecture and other approaches heavily reliant on conceptual modelling have to pass: How can we ensure that these representations truly communicate the essence of systems and facilitate decision making?

2) Applicability across processes and process types: How widely can this approach be applied to other areas? The maturity model has been created by adapting a generic set of conditions, but initial case studies focus on a specific process.

To explore this potential further, we are completing the reported case study and a second case study, and will critically assess the feasibility of a broader application of this approach.

\section{ACKNOWLEDGMENT}

Part of this work has been funded by the Vienna Science and Technology Fund (WWTF) through project ICT12-046 (BenchmarkDP), by Portuguese national funds through FCT Fundação para a Ciência e a Tecnologia, under project PEstOE/EEI/LA0021/2013, and by the European Commission under the IST Programme of the 7th FP for RTD-Project ICT 269940/TIMBUS.

\section{REFERENCES}

[1] P. Harmon, Business process change. Morgan Kaufmann, 2007.

[2] International Organization for Standardization, Space data and information transfer systems - Audit and certification of trustworthy digital repositories (ISO 16363:2012), 2012.

[3] C. Becker and E. Cardoso, "Report on the capability assessment and improvement workshop (CAIW) at iPres 2013," D-Lib Magazine, 2014, http://www.dlib.org/dlib/march14/becker/03becker.html.
[4] Diane L Gibson, Dennis R. Goldenson, and K. Kost, "Performance results of CMMI-Based Process Improvement," Software Engineering Institute, Tech. Rep., 2006.

[5] Software Engineering Institute, Capability Maturity Model Integration for Development. Version 1.3, 2010.

[6] IT Governance Institute, CobiT 4.1. Framework - Control Objectives Management Guidelines - Maturity Models, 2007.

[7] M. Staples, M. Niazi, R. Jeffery, A. Abrahams, P. Byatt, and R. Murphy, "An exploratory study of why organizations do not adopt cmmi," Journal of Systems and Software, vol. 80, no. 6, pp. 883 - 895, 2007.

[8] S. P. Organization, "Software process assessment (SPICE)," 1996. [Online]. Available: http://www.griffith.edu.au/

[9] International Organization for Standardization and International Electrotechnical Commission Std., ISO/IEC 15504 - Information technology - Process assessment - Part 1: Concepts and vocabulary, 2004.

[10] — ISO/IEC 15504 - Information technology - Process assessment - Part 3: Guidance on performing an assessment, 2004.

[11] — ISO/IEC 15504 - Information technology - Process assessment - Part 7: Assessment of organizational maturity, 2008.

[12] The Open Group, "TOGAF 9 - The Open Group Architecture Framework Version 9," The Open Group, USA, p. 744, 2009.

[13] J. Becker, R. Knackstedt, and J. Pppelbu, "Developing maturity models for IT management - a procedure model and its application," Business \& Information Systems Engineering, vol. 1, no. 3, pp. 212-222, 2009.

[14] K. Peffers, T. Tuunanen, M. A. Rothenberger, and S. Chatterjee, "A design science research methodology for information systems research," Journal of Management Information Systems, vol. 24, no. 3, pp. 45-77, 2008

[15] A. Coletta, "An industrial experience in assessing the capability of non-software processes using ISO/IEC 15504," Softw. Process, vol. 12, no. 4, pp. 315-319, Jul. 2007. [Online]. Available: http://dx.doi.org/10.1002/spip.v12:4

[16] B. Barafort, D. Jezek, T. Mkinen, S. Stolfa, T. Varkoi, and I. Vondrak, "Modeling and assessment in IT service process improvement," in Software Process Improvement, ser. Communications in Computer and Information Science, R. OConnor, N. Baddoo, K. Smolander, and R. Messnarz, Eds. Springer Berlin Heidelberg, 2008, vol. 16, pp. 117-128.

[17] The Open Management Group, Business Process Model and Notation (BPMN) - Version 2.0, 2011.

[18] L. Penicina, "Linking BPMN, ArchiMate, and BWW: Perfect match for complete and lawful business process models?" in PoEM (Short Papers), ser. CEUR Workshop Proceedings, J. Grabis, M. Kirikova, J. Zdravkovic, and J. Stirna, Eds., vol. 1023. CEUR-WS.org, 2013, pp. $156-165$.

[19] V. Haren and V. H. Publishing, ArchiMate 2. O Specification, ser. The Open Group. Van Haren Publishing, 2012.

[20] D. Nogicevs, "Application of COBIT maturity model in information security management and arising problematic issues," Datorzinātne un informācijas tehnologijas, p. 53.

[21] B. C. Smith, Limits of correctness in computers. Springer, 1993. 